\title{
Da imagem ao imaginário passando pela imaginação: algumas reflexóes sobre literatura e cinema
}

From image to imaginary through imagination: some reflections on literature and cinema MARIa do RosáRIo Lupi BeLlo ${ }^{1}$

Resumo: 0 presente ensaio toma como ponto de reflexão o conceito de imagem e, através das noções de imaginação e de imaginário, procura analisá-lo através do confronto entre a literatura e o cinema. $\mathrm{O}$ objectivo é estabelecer algumas das premissas que permitam levar a cabo um posterior diálogo sobre o modo como, na contemporaneidade, tal conceito é percepcionado, transfigurado e potenciado, procurando inquirir acerca do impacto e das implicações presentes numa cultura da imagem e da web, tanto em termos de recepção estética quanto de aquisição de conhecimento.

Palavras-Chaves: Imagem; imaginação; imaginário; literatura e cinema.

\begin{abstract}
This essay takes the concept of image as a point of reflection and, through the notions of imagination and imaginary, seeks to analyze it through the confrontation between literature and cinema. The aim is to establish some of the premises that allow for a further dialogue on how, in contemporary times, such a concept is perceived, transfigured and enhanced, seeking to enquire about the impact and the implications which are present in a culture of image and «web», both in terms of aesthetic reception and acquisition of knowledge.
\end{abstract}

Keywords: Image; imagination; imaginary; literature and cinema.

${ }^{1}$ Universidade Aberta; CEG-UAb (Portugal). ORCID ID: https://orcid.org/0000-0002-9638-2773. 


\section{A imagem}

Gostava de partir da obra de Marie José Mondzain, de 2013, sobre o que é «ver e fazer ver», intitulada Homo Spectator. Nela, a autora contrapõe à definição do ser humano como homo sapiens - o homem que sabe - a ideia do homem que vê, homo spectator. Referindo-se às primeiras pinturas rupestres, a autora afirma que «a Paleontologia descobre o homem no momento em que ele se faz ver dando a ver aquilo que nos quis mostrar», um homem que «se apresenta àqueles que virão depois dele como um espectador».

La paléontologie découvre l'homme au moment où il se fait voir en donnant à voir ce qu'il a voulu nous montrer. La naissance de son regard est son adresse au nôtre. Si nous avons quelque chose de cet ancêtre lointain, c'est parce qu'il a laissé ses traces. Des traces de ses gestes, de sa technicité, de son ingéniosité, de l'intelligence dans l'adresse. Mais si la paléontologie nous apprend ce que cet homme savait faire, je propose de faire voir ce que cet homme voyait. Plus encore, je souhaite mettre en scène une fiction vraisemblable et montrer que cet homme se présente aux millénaires qui le suivront comme un spectateur. (Mondzain, 2013: 16)

O termo grego opsis refere-se, por contraposição ao termo logos - que é palavra, mas também pensamento ou razão -, à operação de ver, ou seja, ao órgão da visão. $O$ espectador existe não apenas porque o mundo é espetáculo-e pressupõe,portanto,um destinatário -, mas também porque ele próprio (espectador) é para si mesmo espetáculo e, consequentemente, a sua ação pode (deve) ser vista e ajuizada, compreendida, olhada e pensada, refletida (palavra de duplo sentido, o que é muito pertinente, porque vemos para pensar, para conhecer).

\begin{abstract}
Le spectateur n'est plus alors l'homme qui se sert de ses yeux quand tous ses autres sens sont au repos mais le théatès, celui qui regarde ou contemple ce que le monde ou un autre homme lui donne à sentir pour le lui faire comprendre. C'est un citoyen pris dans le spectacle d'une action qui agit sur lui et dont il fait à son tour quelque chose. Ce quelque chose, qu'il doit à la puissance du logos et non au pouvoir de ses yeux, fait de lui un citoyen en mesure de juger ce qu'il voit et de décider ce qu'il veut avec d’autres. (Mondzain, 2013: 19)
\end{abstract}

$\mathrm{Na}$ verdade, a etimologia da palavra teatro (theatron) assenta precisamente neste pressuposto: na ideia de que se encena aquilo que do mundo se pode ver, o que implica também que o mundo se apresenta como «cenário» que «deseja» ser visto, ou seja, olhado e compreendido (no duplo sentido de abarcado e entendido). $O$ espectador é, assim, aquele que, por via do logos, se empenha em interpretar e ajuizar aquilo que vê e em tirar desse juízo as ilações necessárias à sua vida e ao seu agir. O espectador nasceu, como defende Mondzain, quando o homem das cavernas se afastou para olhar para as mãos que imprimira na parede. A imagem é fruto da separação e da 
alteridade, pressupõe afastamento e distância, perspetiva. Ao retirar a mão para ver, o homem das cavernas «cenarizou» a composição do seu primeiro olhar, transformando a imagem em imagem cénica - as implicações artísticas e estéticas deste gesto são óbvias.

Um primeiro aspeto que gostaria de frisar é este: a perceção de que o ser humano revela, desde o início, que é importante olhar, e que, portanto, as imagens têm um papel decisivo. Ao construir, ainda que de forma incipiente, uma primeira imagem, o homem revela a perceção de um sentido, isto é, de uma relação entre ele e as coisas; se quisermos simplificar, diremos que percebe que as coisas são para ele. É no ponto em que se deixa tocar, «afetar» (em que se estabelece uma afeição, um interesse), que esse sentido emerge com maior evidência. As imagens servem, portanto, à construção de um significado sobre a existência e sobre o lugar do humano no mundo.

Para nós, seres humanos, o mundo não é um conjunto de meras coisas que vemos e às quais atribuímos significado, mas antes vemos esse significado por assim dizer «diretamente»e numa relação significativa com o seu contexto (se eu me encontrar a expor uma comunicação em cima de um estrado, percebo que aquelas saliências de pedra que ligam o estrado ao chão não são casuais nem aleatórias - são os degraus pelos quais posso subir ou descer). Por outras palavras: nós existimos numa paisagem de significado.

Porém, é importante compreender uma outra dimensão de que fala também Mondzain: ela distingue a imagem natural do ícone. A imagem natural é invisível, é o mistério; só o ícone oferece visibilidade (ao enigma). Para Marie-José Mondzain, a relação «económica» do ícone artificial com a imagem natural é a da função da visibilidade na sua ligação com a imagem invisível, que é a única verdadeira. E acrescenta Mondzain (1996: 110):

\begin{abstract}
L'essence de l'image n'est pas la visibilité, c'est son économie et elle seule qui est visible en son iconicité. La visibilité appartient à la définition de l'icône et non pas à celle de l'image. [...] L'icône vise la ressemblance avec son prototype sans prétendre entretenir avec lui la relation de similitude que celui-ci entretien avec sa propre substance. ${ }^{2}$
\end{abstract}

De facto, etimologicamente a palavra «imagem» está ligada à raiz de imitari e implica a noção de analogia, de relação de íntima semelhança com o objeto representado, no fundo, de «cópia».

\footnotetext{
2 Mondzain não deixa de levantar a pertinente pergunta: «Comment donc l'image artificielle sera-t-elle semblable au Verbe?», à qual responde de forma clara e definitiva: «Car, si le Verbe de Dieu a élu le visible et la chair pour distribuer le salut de l'image par l'image, il nous reste à témoigner de cette élection de la chair pour rendre à jamais présent et visible le mémorial de notre rédemption. Qui refuse l'icône refuse de ressusciter». (Mondzain, 1996: 110).
} 
De qualquer forma, falar de imagem pressupõe sempre uma seleção (esta ou aquela imagem ou imagens) e uma delimitação (a imagem não se confunde com a totalidade da experiência, mas destaca-se dela através dos seus contornos e limites específicos, tanto que é passível de descrição e análise), bem como a intervenção de um processo de fixação - que pode ser natural (e aqui usa-se a palavra num sentido literal diferente do anterior, ou seja, da natureza), como é o caso da memória, da imaginação ou do inconsciente humanos, ou «artificial» (construído), como é o caso da mão impressa na rocha, da pintura na tela, ou de um qualquer processo mecânico, como por exemplo a fotografia, a filmagem ou a reprodução no ecrã.

\section{Imagem versus palavra}

W.J.T. Mitchell, numa obra de reconhecido valor expositivo e sintético, Iconology. Image, Text, Ideology, distingue cinco ramos da família das imagens - as quais manifestam sempre uma "semelhança» ${ }^{3}$ com o objecto («protótipo») que reproduzem: gráfico (pinturas, estátuas, desenhos), ótico (espelhos e projeções), percetual (dados sensoriais, «species»", aparências - como acontece num filme), mental (sonhos, memórias, ideias, «fan- tasmata $\aleph^{5}$ ) e verbal (metáforas, descrições). Vamos, pois, concentrar-nos sobretudo (embora não só) nas imagens verbais e percetuais, já que tratamos de literatura e de cinema, de escrita e de registo audiovisual.

Paul Ricoeur fala do valor da imagem construída pelo ser humano ao discutir a questão do ícone e da iconicidade da imagem, recorrendo a Platão e à comparação estabelecida, no Fedro, entre a escrita e a pintura (Ricoeur, 1987: 49-54). Para o filósofo grego, as imagens de ambas - pintura e escrita - são mais fracas e menos reais do que os seres vivos, na medida em que apenas reproduzem a sua sombra, exteriorizando e, portanto, contrariando o processo interior da reminiscência. 0 resultado torna-se uma simples rememoração, que não coincide com a realidade, mas apenas com a semelhança dela: não se trata de sabedoria, mas da sua aparência. Ricoeur propõe um conceito diverso de pintura, que não coincide com a mera reduplicação umbrática da realidade, mas antes se define, pelo contrário, como «aumento icónico» dessa realidade, através da estratégia de reconstrução do real com base num alfabeto ótico limitado:

\footnotetext{
${ }^{3}$ Mitchell (1987:10) usa os termos «likeness», «resemblance», «similitude».

${ }^{4}$ Mitchell utiliza este termo segundo a conceção aristotélica, que diz respeito àquelas «formas sensíveis» que emanam dos objetos e se imprimem nos nossos sentidos «como um anel de sinete».

${ }^{5}$ «[...] versões revividas dessas impressões convocadas pela imaginação na ausência dos objectos que originalmente as estimularam» (Mitchell, 1987: 10).
} 
Deste modo, o principal efeito da pintura é resistir à tendência entrópica da visão ordinária - a imagem umbrática de Platão - e aumentar o sentido do universo apreendendo-o na rede dos seus signos abreviados. Este efeito de saturação e culminação, dentro do pequeníssimo espaço de uma moldura e na superfície de uma tela bidimensional, em oposição à erosão óptica própria da visão ordinária, é o que é significado por aumento icónico. [...] A iconicidade significa, pois, a revelação de um real mais real que a realidade ordinária. (Ricoeur, 1987: 52)

De acordo com esta conceção de iconicidade como «aumento estético da realidade», segundo o filósofo francês, a própria escrita surge como «um caso particular de iconicidade», na medida em que «a inscrição do discurso é a transcrição do mundo e a transcrição não é reduplicação, mas metamorfose», metamorfose essa que evidencia a própria realidade. Escrever é reescrever a realidade de modo estético e revelador da sua essência. Continua Ricoeur:

O valor positivo da mediação material pelos signos escritos pode atribuir-se, tanto na escrita como na pintura, à invenção de sistemas de notação que apresentam propriedades analíticas: descontinuidade, número finito e poder combinatório. (Ricoeur, 1987: 54)

Torna-se, pois, possível deduzir acerca da forte iconicidade dessa particular «escrita» que é a imagem cinematográfica, e que alguns autores comparam com a linguagem verbal a fim de destacarem as suas características específicas:

O signo verbal, com a sua baixa iconicidade e a sua elevada função simbólica, funciona conceptualmente, enquanto que o signo cinematográfico, com a sua elevada iconicidade e a sua incerta função simbólica funciona directamente, sensoriamente, perceptualmente. (McFarlane, 1996: 27)

Desta dimensão «percetual» faz parte a cor, sinal indesmentível da presença da luz, que é a matéria de que é feita a imagem cinematográfica. Mondzain (2013: 43) lembra a frase de Aristóteles em Tratado da alma: «O objecto da vista é o visível. O visível é côr e é também o que é possível de enunciar pela palavra apesar de não ter nome». Mais do que poder dos olhos, o visível é sobretudo poder do pensamento.

O ponto que queria aqui sublinhar é esta distinção na natureza das imagens literárias e das imagens fílmicas ou cinematográficas: o leitor tem acesso a um «mundo possível» através de signos arbitrários escritos que sugerem imagens significativas (imagens mentais), enquanto que ao espectador é mostrado um mundo possível através de signos icónicos audiovisuais. Muitos sintetizam esta diferença fundamental através da oposição da situação de telling à de showing, frisando, como François Jost: «A imagem [cinematográfica] mostra, mas não diz». 
Os estudos das relações entre literatura e cinema permitiram verificar que, ao longo do tempo, houve frequentemente a tendência para hipervalorizar a relação entre a imagem percetual e o seu arquétipo, levando a uma comparação com a palavra que colocou esta em desvantagem, criando uma espécie de hostilidade. Tal hostilidade tem que ver com a noção subentendida de que a diferença (entre palavra e imagem - percetual, fotográfica ou cinematográfica) coincide com aquela que existe entre os símbolos e o mundo, ou os sinais e o seu significado. É o que Mitchell refere nas seguintes linhas:

Imaginamos o abismo entre as palavras e as imagens como sendo tão largo como aquele que existe entre as palavras e as coisas, como entre (no sentido mais lato) a cultura e a natureza. A imagem é o sinal que finge não ser um sinal, mascarando-se (ou, para o crente, conseguindo constituir-se realmente) como imediatez e presença naturais. A palavra é o «outro», o artificial, a produção arbitrária da vontade humana que rompe a presença natural ao introduzir elementos não naturais no mundo - o tempo, a consciência, a história e a intervenção alienante da mediação simbólica. (Mitchell, 1987: 43)

Esta posição liga-se à conceção da imagem enquanto elemento primitivo da existência, referência última no espírito humano, subjacente, e portanto anterior, às palavras e às ideias. Wittgenstein procurou erradicar esta noção da filosofia da linguagem, assim como os behavioristas o fizeram no campo da psicologia.

No campo artístico, o filósofo Romano Guardini afirma que as imagens têm extrema importância, já que o artista se encontra numa condição semelhante à da criança e do profeta, uma vez que não é, pelo menos num primeiro momento, guiado por um juízo crítico nem por uma vontade finalística, como acontece na vida do homem comum, mas «nele a vida é simultaneamente excitada e relaxada, desperta e ao mesmo tempo receptiva, aberta tanto ao objecto do mundo exterior quanto à própria interioridade». «Nestas condições de espírito podem emergir as imagens: não conscientemente pensadas e queridas, mas sim entretecidas naquilo que nesse momento toma forma». Mais do que anteriores à palavra e à obra de arte, as imagens - essas «figurações originais» - são-lhes inerentes e vibram através do poema, da peça musical, da construção arquitetónica, etc. «Por isso a representação artística adquire um peso que supera em grande medida o significado mais evidente» (Guardini, 1954).

De qualquer forma, quer num sentido quer noutro, aquilo que não podemos deixar de constatar é o valor polissémico de qualquer imagem. Quer se trate de um sonho, de um desenho, de uma imagem verbal ou de um fotograma, cabe ao recetor da imagem avaliar do seu significado, podendo, da variedade possível que se the depara, escolher uns e ig- 
norar outros. E a palavra desempenha, neste processo, um papel fundamental.

Pensando no caso do cinema, é corrente a afirmação de que o enunciado verbal pode ter uma correspondência (pelo menos ao nível do significado) no plano cinematográfico, mas que o inverso não é verdadeiro, porque o plano contém virtualmente uma pluralidade de enunciados narrativos que se sobrepõem. Analisando o problema específico da imagem publicitária, Roland Barthes define-a como constituída por três tipos de mensagens (linguística, denotativa e conotativa), atribuindo à mensagem linguística a capacidade de fixação do(s) sentido(s), através de uma dupla função: a de «ancoragem» e a de «etapa» (cf. Barthes, 1977: $32-51)^{6}$

O que importa reter da teoria barthesiana é a constatação de que a imagem visual, no plano da significação, tem necessidade da palavra como factor de fixação do sentido. Esta clarificação é de extrema importância quando se trata da abordagem à imagem ci- nematográfica, por duas razões essenciais: em primeiro lugar, porque se verifica que a conotação e o simbolismo (e a consequente plurissignificação que implicam) não são mero atributo dos signos verbais, mas encontram-se também nos visuais (e, por consequência, nos cinematográficos), o que se traduz numa implicação mútua (não apenas porque o signo visual requer o contributo do verbal, mas também porque a palavra remete para a imagem $)^{7}$; em segundo lugar, porque é imprescindível não simplificar a questão da iconicidade da imagem visual, reduzindo esta característica a uma capacidade analógica exclusivamente visual. ${ }^{8}$

Um dos aspetos fundamentais a considerar tem que ver com o facto de a imagem conceptual produzida pelo signo verbal evidenciar uma maior indefinição, um mais elevado grau de fluidez do que a imagem visual (nomeadamente a cinematográfica). Esta última caracteriza-se, pelo contrário, por um elevado índice de «especificação» (o termo inglês usado por

\footnotetext{
${ }^{6}$ Barthes chama, primeiramente, «mensagem» a cada um destes três tipos, admitindo que a totalidade da imagem publicitária (que é aquela onde a significação é inequivocamente intencional) é constituída por três diferentes imagens. Mas explica seguidamente que a sua tarefa é a de «Reconsiderar cada tipo de mensagem, a fim de a explorar na sua generalidade, sem perder de vista o [seu] objectivo, que é o de compreender a estrutura global da imagem, a inter-relação final das três mensagens» (Barthes, 1977: 37).

7 É deste «mecanismo de implicação» mútua que fala Keith Cohen, afirmando seguidamente: «a narratividade é o elo de mediação mais sólido entre o romance e o cinema, a tendência mais difundida tanto na linguagem verbal como na visual. Quer no romance quer no cinema, grupos de signos, sejam eles literários ou visuais, são apreendidos consecutivamente através do tempo; e esta consecutividade dá origem a uma estrutura que se desenrola, o conjunto diegético que nunca está totalmente presente em nenhum grupo mas que está sempre implicado em cada um deles» (apud Naremore, 2000: 34).

${ }^{8}$ Paulo Filipe Monteiro alerta, precisamente, para o risco de se cair numa visão simplista, que cole o cinema unicamente à imagem, ou, pelo contrário, que o defina como texto em sentido estrito - para não falar da visão essencialista, que já provou a sua fraca fecundidade teórica (cf. Monteiro, 1995: 502-514).
} 
alguns autores é «over-specification»), na medida em que é «levada» a reproduzir todos os elementos da realidade física que capta. É curioso notar que Ricoeur estabelece este paralelo ao distinguir entre a visão ordinária e aquela proporcionada pela pintura, com vista à demonstração do referido aumento icónico que esta última acarreta. ${ }^{9}$ Também no capítulo sobre a adaptação da literatura ao ecrã teremos oportunidade de referir este aspecto, que, se por um lado confirma a maior iconicidade estética da imagem cinematográfica em relação à literária, por outro é (ou pode ser) paradoxalmente causador, também, de um certo sentimento de «redução» ou «aglutinação» em relação à imagem conceptual, que se vê «forçada» a um maior grau de definição, a uma necessária e efetivada «selecção».

O que temos vindo a sublinhar, portanto, é o risco de reduzir a distinção entre literatura e cinema à oposição entre o signo arbitrário da literatura e o signo icónico do cinema (i.e., entre palavra e imagem - como se a primeira nada tivesse de icónico e a segunda fosse o espelho de uma analogia perfeita), comparação que tem frequentemente levado a ambiguidade e a erros de análise, por simplificar demasiadamente o grau de complexidade ontológico de cada um dos casos, além de esquecer que a palavra não está ausente do filme.

\section{A questão do tempo}

Importa, porém, referir ainda um outro aspeto de não menor importância e que permite aprofundar a compreensão da natureza da imagem cinematográfica. A imagem ótica de que é constituído o cinema não pode ser retirada do seu contexto, que é o do movimento e, consequentemente, o da temporalidade, razão pela qual ao falar de cinema se torna essencial falar de «imagem temporalizada» - num sentido exemplarmente descrito por Deleuze na sua famosa obra dupla, L'Image-Temps e L'Image-Mouvement.

Boa parte da importância da teoria deleuziana reside na conceção de cinema que dela decorre - para este filósofo, a imagem cinematográfica não tem correspondência possível no enunciado verbal, porque este não possui a característica do movimento. 0 cinema não pode, portanto, definir-se como língua nem como linguagem, uma vez que é constituído por uma matéria inteligível, mas não linguisticamente formada, que é condição ou correlato (formado pelos movimentos, pelo pensamento expresso nas imagens pré-linguísticas, pelos pontos de vista) a partir do qual a linguagem constrói os seus próprios objetos (as suas unidades e as suas operações significativas) (Deleuze, 1985: 342). Para Deleuze o cinema

\footnotetext{
${ }^{9}$ Diz Ricoeur (1987: 52): «Enquanto na visão ordinária as qualidades tendem a neutralizar-se umas às outras, a esbater as suas arestas e a apagar os seus contrastes, a pintura, pelo menos desde a invenção da pintura a óleo pelos artistas holandeses, realça os contrastes, restitui às cores a sua ressonância e deixa aparecer a luminosidade, dentro da qual as coisas brilham».
} 
não é língua nem linguagem - a menos que a própria realidade possa ser concebida desse modo. Ou antes, como diria Pasolini, se se considerar que o cinema é a língua da realidade.

Concordamos que o cinema não é uma língua no sentido em que a sua natureza não se estrutura linguisticamente, mas tal constatação não coincide nem pode coincidir com uma negação da sua capacidade narrativa. Aliás, o próprio Deleuze esclarece que a narração não é um dado das imagens nem um efeito da estrutura que as fundamenta, mas sim uma consequência.

Ao reproduzir uma propriedade essencial da natureza, a imagem em movimento «atinge» o espetador com uma capacidade persuasiva e uma sugestão de realidade («impressão de realidade», nas palavras de Christian Metz) muito maior do que a imagem fixa. Bazin defendia, por esta razão, o realismo da imagem cinematográfica, cuja principal qualidade consistia, por isso mesmo, em revelar a essência do real, na medida em que esse movimento integrasse e respeitasse o tempo real das coisas, a duração dos acontecimentos. André Bazin chegou mesmo a afirmar que o cinema é o contrário da pintura, mas que entre romance e filme não existe essa contradição, já que são ambos artes da narrativa, do tempo, e têm, portanto, como principal tarefa a sugestão de um mundo real ou, como diria Flannery O'Connor, «um mundo em acção» (O’Connor, 1997: 79).

\section{O Problema da certeza}

Gostava de introduzir aqui um parêntesis para suscitar um outro ponto de reflexão, talvez um pouco lateral, mas que tem alguma relação com o atrás exposto. A saturação de imagens em que vivemos atualmente - potenciada pelo fenómeno da Internet e pelo uso quotidiano dos telemóveis, iPhones, iPads, etc. facilitou uma atitude muito contemporânea, e que podemos detetar no velho conflito entre ciências e humanidades, ou, melhor dizendo, na atual posição de desvantagem das humanidades face às ciências empíricas. A impressão de realidade que a imagem visual em geral e a imagem em movimento em particular causam assenta bem dentro de uma cultura ainda muito marcada pela herança iluminista e portanto com a tendência para hipervalorizar os dados considerados objectivos e «seguros», em oposição aos dados considerados subjetivos e voláteis, inseguros.

A noção implicada na hipervalorização de uma certa forma de conhecimento (seja o científico stricto sensu, seja o das imagens que nos rodeiam e das redes sociais - que funcionam como uma - aparente - forma de validação do conhecimento) é a de que tal objetividade dispensaria a interferência «perniciosa» do elemento subjetivo, instável e «perigoso», ou melhor, dispensaria a própria tomada de decisão, o uso pessoal da liberdade. Assim, é assumida como posição pessoal a absorção acrítica dos «factos» apresentados «objetivamente» 
na sociedade das imagens e dos media, estabelecendo-se aquela grave confusão de que falou Derrida: «Já não há factos, apenas opiniões». Ora, nem sequer a ciência pode prescindir de uma interpretação pessoal, «a visão científica está sempre sujeita a uma determinada moldura teórica». ${ }^{10}$

O problema de fundo tem que ver com a confusão entre a alternativa objetividade versus subjetividade e a alternativa certeza (absoluta) versus opinião (relativa). Existe, de facto, uma noção muito difundida de que posso ter a certeza sobre uma descoberta da ciência, mas só posso ter uma opinião no caso de todos os outros tipos de conhecimento. Mas, no fundo, a alternativa que se esconde nesta dualidade é entre a possibilidade ou a impossibilidade de conhecimento real. 0 cientismo tem sido, como sabemos, a tentativa de trazer para fora do domínio das ciências exatas as certezas que supostamente só pertencem à ciência. Obviamente, esta alternativa é falaciosa, nos dois sentidos: não apenas a certeza científica é falível e mutável, como é possível obter certezas muito razoáveis noutros campos do conhecimento, nomeadamente nas humanidades. A razão humana é bem mais ágil do que o positivismo e o cientismo pretendem, pois não necessita, forçosamente, da experiência empírica, da prova matemática ou mesmo do silogismo filosófico para obter certezas. Este facto é facilmente verificável (embora não demonstrável por nenhum desses três processos) no caso do comportamento humano (posso ter uma certeza muito sólida sobre o facto de a minha mãe me amar, sem aplicar nenhum daqueles critérios). É importante reconhecer um traço característico da nossa época: uma redução do valor da razão. Vivemos um tempo dominado pelo sentimentalismo e pela desinformação, que nos tornam sujeitos muito facilmente manipuláveis - e bem sabemos como a Internet e as redes sociais podem exponenciar este problema. Além disso, o sujeito moderno tem tendência a ignorar o nexo entre a realidade e a própria vida, o que o leva a interessar-se sobretudo pelo acessório, tornando-se presa fácil dos interesses comerciais, políticos e ideológicos, que fazem «querer» e «acreditar» em determinadas coisas como se resultassem de escolhas conscientes, profundas e certas. Naturalmente, há nesta problemática, de contornos dramaticamente pós-modernos, uma clara redução do valor da «verdade» conceito difusamente empobrecido e visto como dogma ou como sintoma de intolerância sempre que não seja justificado pela certeza científica, ou encarado como inútil e indesejável, como impossibilidade cognitiva (se não

\footnotetext{
${ }^{10}$ Este ponto foi argumentado de forma particularmente clara na conferência apresentada pelo historiador da Ciência Henrique Leitão, na Faculdade de Ciências Sociais e Humanas da Universidade Nova de Lisboa, em maio de 2010, com o título «Porque é que o “English Galileo" não viu o que Galileu viu?».
} 
pudermos ter razoáveis certezas ou suficiente confiança, não entramos em contacto com o real). Por isso, no campo da literatura e das artes julga-se poder defender qualquer posição, já que parece estar-se no território da pura opinião, sem necessidade de validação da verdade - o que é falso -, enquanto no campo da ciência e da técnica nenhuma discussão é permitida, uma vez que o âmbito é o da certeza radical e indiscutível. 0 resultado, bem o sabemos, é o da difusão de um relativismo geral, cuja face é dupla: a fraqueza da certeza «moral» (no sentido etimológico, de comportamento e de ação) e o totalitarismo cientista (aplicado também a dimensões não científicas, que se tornam território de pensamento dominante e indiscutível).

Porém, a certeza «moral», que é aquela realmente necessária à vida, só pode resultar de uma aprendizagem crítica, para que possamos entender-nos uns aos outros e à própria existência (sem razoáveis certezas nesse âmbito não existe confiança vital nem é possível o verdadeiro contacto com o real). A «sociedade da imagem» não pode prescindir do pensamento crítico: ele é que verdadeiramente a defende tanto do cinismo quanto do relativismo radical e cego. $\mathrm{O}$ realizador alemão Harun Farocki (editor da revista Filmkritik) faz uma constante reflexão crítica sobre as imagens:
Il faut être aussi méfiant envers les images qu'envers les mots. Images et mots sont tissés dans des discours, des réseaux de significations. Ma voie, c'est d'aller à la recherche d'un sens enseveli, de déblayer les décombres qui obstruent les images. ${ }^{11}$

Na verdade, se o conhecimento não incrementa o «eu», é irrelevante. Ultimamente, tal incremento implica, naturalmente, a pergunta sobre o significado, sobre o nexo entre si e o mundo.

No confronto entre ciências e humanidades, há quem, como Dilthey, estabeleça a alternativa entre o conceito de «explicação» e o de «compreensão» (incluindo este a noção de sentido ou significado).Seja como for,é importante ressalvar que a racionalidade não é o uso frio da razão, mas sim o modo como vivemos no real. Da mesma forma, é fundamental compreender que - como diz o (demasiadamente famoso...) historiador israelita Yuval Noah Harari, em 21 lições para o século XXI-, a consciência é mais do que a inteligência, pois ela não se limita a resolver problemas, como por exemplo o dos robots e da inteligência artificial, mas tem que ver com a experiência humana: com o medo, a alegria, o amor, a raiva, etc. - ou seja, com a realidade que nos «toca», e portanto é fundamental não perder o elo de relação entre a racionalidade e a afetividade.

\footnotetext{
${ }^{11}$ Estas palavras foram publicadas no catálogo da retrospetiva da sua obra, organizada em 2001 no Cineclube de Münster, na Alemanha.
} 
Neste sentido, é muito interessante verificar que tanto a imagem imaginária sugerida pela literatura narrativa quanto a imagem percetual oferecida pelo cinema podem dar um contributo muito significativo, sobretudo se atendermos ao valor ontológico da narrativa.

\section{Matéria e conteúdo da expressão narrativa - uma unidade significativa com uma vocação concreta}

A diferença óbvia entre a matéria de expressão da narrativa literária (palavra) e a da narrativa fílmica (imagem audio-visual temporalizada) tem levado, aos poucos, à instalação de uma noção tácita e geralmente aceite, que é a da oposição entre o que se considera a dimensão abstrata da literatura (que se baseia no valor convencional, arbitrário e simbólico da palavra) e a dimensão concreta do cinema (devido à forte iconicidade e ao poder analógico da imagem fotográfica). Parece-nos que nos devemos deter neste ponto, porque o consideramos muito pertinente e porque não concordamos com a formulação da questão nestes termos.

No prefácio à edição portuguesa de $A$ obra de arte literária de Ingarden, Maria Manuela Saraiva recorda a formulação clássica: Nihil est in intellectu quod prius non fuerit in sensu (em Ingarden, 1979: XXXVII). Ora, a narrativa lite- rária procura, precisamente, a representação, evidentemente modificada, dessa experiência sensível. Na nossa opinião, toda a obra de arte narrativa, seja ela literária ou cinematográfica, caracteriza-se por se orientar para o «concreto», já que constitui precisamente a representação de uma experiência, isto é, tem como ponto de partida - e, de algum modo, também como ponto de chegada - os sentidos humanos, que são o primeiro e essencial instrumento de conhecimento. Narrar acontecimentos implica reproduzir o seu ambiente natural, que são os lugares, os tempos, as cores, os sons, as formas, através dos quais se transmitem significados, sentimentos e emoções. ${ }^{12}$

É num sentido idêntico que uma autora como Flannery O'Connor afirma, de modo inteligentemente sintético, que a narrativa ficcional é uma «arte encarnatória» (O’Connor, 1997: 68). Para O'Connor, o mínimo denominador comum da narrativa - e note-se que ela se refere sobretudo ao romance e ao conto - é exatamente o facto de ser «concreta», embora seja este $o$ aspeto tantas vezes incompreendido pelos escritores principiantes ou pelos maus escritores:

Eles estão conscientes de problemas, não
de pessoas, estão conscientes de questões e
temas, não da textura da existência, de casos

\footnotetext{
12 Lembremos a definição hegeliana acerca da «totalidade dos objetos» comunicados pela narrativa, cuja representação consiste em «uma esfera da vida real, com os aspectos, as direcções, os acontecimentos, os deveres, etc., que ela comporta» (Hegel apud Aguiar e Silva, 1990: 202).
} 
e de tudo o que tem um impacto sociológico, em vez de o estarem acerca de todos aqueles pormenores concretos da vida que tornam presente o mistério da nossa posição na terra. (O'Connor, 1997: 68)

\section{Da imaginação ao imaginário}

Vale a pena citar uma frase de Roman Ingarden, na qual o filósofo polaco, referindo-se à leitura literária, afirma que o papel da imaginação, não sendo sensorial em sentido estrito, nasce daí (dos sentidos) e, embora modificando a objetividade apresentada, funciona por referência a ela:

Os aspectos impostos ao leitor durante a leitura nunca podem ser actualizados como dados autenticamente na percepção mas apenas na modificação da fantasia, embora na própria obra em geral sejam determinados como percepcionáveis. São, porém, sugeridos ao leitor apenas por meios artificiais e não pertencem às objectividades verdadeiramente reais mas apenas às objectividades puramente intencionais e quase-reais segundo o seu conteúdo. Os aspectos actualizados ao nível da fantasia têm como infra-estrutura apenas um material quase-sensorial que apesar da sua actualidade por essência se distingue dos autênticos dados sensoriais. (Ingarden, 1979: 294-295)
É importante notar que na obra em si os «aspectos» são «determinados como dados na perceção», e são as «condições particulares da leitura» que levam a inevitáveis modificações.

Interessa-nos lembrar estes conceitos na medida em que implícita ou explicitamente apontam para a dimensão literária de sugestão do universo exterior e concreto (o que não nega nem subestima o contributo do universo interior e psíquico do escritor e do leitor, sem os quais, aliás, não faria sentido expor o acima dito). $O$ cineasta João Mário Grilo, num colóquio que teve lugar na Universidade Nova de Lisboa, ${ }^{13}$ frisava que a literatura designa os objetos através das ideias, enquanto o cinema designa as ideias através dos objetos. Esta distinção, que tem o valor de sublinhar a presença inevitável e concreta desses «objectos» (nomeados ou representados), deve ser entendida na medida em que se compreenda que não são apenas ideias em sentido estrito ou filosófico aquilo que é directa ou indirectamente designado através da literatura (narrativa) ou do cinema, mas antes essências ou, se se quiser dizer de outra forma, conteúdos, significados, materializados na forma artística. O modo de os exprimir, quer seja na narrativa literária quer seja na narrativa fílmica, é através dos objetos concretos referidos e

\footnotetext{
13 Tratou-se de um curso livre intitulado «Diálogos da Literatura com outras artes e saberes», organizado por Teresa Rita Lopes, Ana Paula Guimarães e Inês de Ornellas e Castro, que decorreu na Faculdade de Ciências Sociais e Humanas da UNL de 10 de Janeiro a 23 de maio de 1995, com uma periodicidade semanal. A sessão referida acima, «Texto e Imagem III», teve lugar no dia 7 de fevereiro e nela tomaram parte, além de João Mário Grilo, Fernando Cabral Martins, João Botelho e José Álvaro Morais.
} 
sugeridos por uma (através de imagens conceptuais) e mostrados (através de imagens percetuais) pela outra.

Em ambos os casos o trabalho da leitura, ou seja, da interpretação, é absolutamente indispensável, e dele faz parte a componente da imaginação, ou seja, a produção pessoal de imagens que estabeleçam algum tipo de relação pertinente com os objetos vistos ou sugeridos, assim reconstruindo o mundo encontrado através do estabelecimento do seu significado.

Para André Bazin a imagem não conta pelo que acrescenta à realidade, mas sim pelo que dela revela (Bazin, 1992: 76). A sua posição como teórico do cinema é, como se sabe, de natureza ontológica e de fundamento realista. 0 que lhe interessa é a relação do cinema com o real, isto é, a particular possibilidade que o cinema tem de revelar o sentido da realidade, o significado concreto e essencial - que nada tem que ver com a mera captação da aparência, com a ilusão das formas, a que Bazin chama o «pseudo-realismo». O homem tem naturalmente um imenso desejo de defesa contra o tempo e a morte, que se revela numa autêntica obsessão pelo real, pela reprodução e fixação das coisas enquanto processo de «salvação» do ser pela aparência, manifestados ao longo do tempo, primeiramente na pintura e depois na fotografia. O cinema, participando da capacidade fotográfica de «transferência da realidade da coisa para a sua reprodução» (cf. Bazin, 1958: 43, apud Monteiro, 1996: 69) e acrescentando-lhe a dimensão temporal, que reproduz uma propriedade essencial da natureza - o movimento -, torna-se a expressão realista por excelência. ${ }^{14}$ Se a fotografia já teve o enorme mérito de permitir «que a pintura ocidental se desembaraçasse definitivamente da obsessão do real e reencontrasse a sua autonomia estética», o cinema é «o resultado final no tempo da objectividade fotográfica» (Bazin, 1992: 21 e 19).

Alguns escritores, como Joseph Conrad (com a sua famosa frase «A minha tarefa é fazer-vos ver») e Henry James, entre outros, particularmente do período modernista, defenderam a ambição da literatura em produzir imagens, em fazer «ver» - facto que justifica a enorme quantidade de romances transpostos para o cinema: a leitura literária «pede» uma concretização, sugere, através da imaginação, uma corporização, promete alguma coisa à qual a imagem audio-visual procura responder. Para Herbert Read a qualidade «visual» é o objetivo último tanto da literatura como do cinema: «...transmitir imagens. Fazer com que a mente veja».

Por outro lado, a literatura não apenas nasce da observação (Flannery O’Connor fala mesmo

${ }^{14}$ Bazin (1992: 20) apelida, por isso, o cinema, de «múmia da aparência». 
de contemplação ${ }^{15}$ ) como pede do leitor um idêntico trabalho no aprofundamento do olhar. O ponto de vista do autor solicita o leitor a tomar, também ele, uma posição, partilhando ou recusando a que lhe é proposta. No fundo, ler um romance é aceitar fazer uma experiência, porque é ver acontecer alguma coisa, tanto fora como dentro de si. Por isso pode considerar-se que o «acontecimento»é a categoria decisiva da narrativa, o seu motor e o cerne da sua natureza mais profunda.

Se a conceção da narrativa literária como olhar sobre o mundo - um mundo em ação, em permanente mudança, dentro do espaço e do tempo - nem sempre é sublinhada com a necessária clareza e intensidade, a posição que considera a natureza do cinema como visão desse mundo não causa qualquer perplexidade e é, pelo contrário, repetidas vezes encarada como a própria definição do objeto cinematográfico. Porém, quer num caso, quer no outro, o que é essencial é não esquecer que a visão desse mundo não é mera perceção «física» (mesmo no caso do cinema), mas antes lugar de acontecimentos simultaneamente visíveis e invisíveis, físicos e espirituais, «revelação das qualidades metafísicas predeterminadas na própria obra», como diria Ingarden (1979: 373).
O imaginário pode ser definido precisamente como a representação do mundo por recurso a um determinado conjunto de imagens que the atribuem sentido; é, pois, uma construção e interpretação do real. Constituído por imagens, narrativas, símbolos, o imaginário confere identidade a um grupo de pessoas, a uma comunidade, a um país, a um Estado-nação, na medida em que as congrega sob esse conjunto de significados e valores comuns.

\section{Imaginação e ficção científica}

Quando se pensa na relação criativa que a literatura e o cinema manifestam, verifica-se que um território comum e particularmente dependente da imaginação e do imaginário é a ficção científica. Dentro deste vasto universo, o campo talvez mais intrigante e desafiante é o que incide na análise especulativa da mente humana, particularmente no que diz respeito ao estudo da memória e dos sonhos, que tem constituído terreno de profunda investigação, tanto na área da psicologia e da neurociência quanto no âmbito da filosofia. Tal interesse liga-se, naturalmente, ao carácter profundamente complexo e até misterioso desses processos, por um lado, e, por outro, à pertinência que eles têm na determinação da identidade pessoal e, portanto, nas implicações de natureza subjetiva e nas suas consequências éticas.

\footnotetext{
${ }^{15}$ A sua frase é: «O dever do escritor é contemplar a experiência, não dissolver-se nela» (O’Connor, 1998: 352).
} 
Por isso mesmo a ficção científica, marcada que é por uma forte atração pelos territórios mais inexplorados ou misteriosos da ciência e da natureza humana, tem mostrado interesse na abordagem dessas complexas temáticas. $\mathrm{Na}$ verdade, sonhos e memória são, de todos os «lugares» fantásticos, aqueles que se apresentam mais longínquos, recônditos e difíceis de explorar, constituindo o acesso a eles a viagem mais aventurosa e arriscada (mas também, por isso mesmo, a mais desejada), na qual se coloca em causa a própria natureza e inviolabilidade da pessoa, a questão da definição e da identidade do humano, a fronteira entre sonho e desejo de felicidade (nomeadamente através da vitória sobre o tempo), a possibilidade da eternidade e de Deus, a pergunta sobre o conhecimento e a verdade.

O território da ficção científica é um universo de proporções imensas. É difícil quantificar a enorme diversidade de livros e de filmes escritos, realizados e classificados sob esta designação. Se para alguns a denominação «ficção científica» remete para mundos demasiadamente imaginosos, repletos de absurdo irrealismo ou fantasia vagamente infantil, para muitos o termo evoca um género literário ou fílmico razoavelmente bem definido, com grande poder de atração, no qual estão incluídas muitas obras francamente admiradas, por vezes mesmo cultivadas com autêntica devoção.

A terminologia («ficção científica») é interessante, porquanto assume uma espécie de tácita contradição nos termos: trata-se de «ficção», isto é, está-se no território da cultura enquanto construção imaginosa, inventiva, fruto da criatividade e subjetividade humanas, mas, por outro lado, trata-se de uma ficção «científica», isto é, que tem a pretensão de lidar com o território da ciência enquanto construção objetiva, demonstrável empírica ou matematicamente - aqui se trava, pois, uma pertinente batalha entre os conceitos já aludidos, ou seja, certeza e incerteza, objetividade e subjetividade, racionalidade e emoção. Torna-se razoável admitir a hipótese de que não exista ficção «pura», nem sequer pura ciência, já que a primeira precisa da realidade concreta tanto quanto a segunda necessita da imaginação. Roman Ingarden (1979: 374-375) alerta para o «risco» de uma ficção sem ancoragem no real, o que significaria a morte da própria obra:

\footnotetext{
Quando nós [...] somos [...] obrigados a pensar que nos acontecimentos e nos objectos representados se trata de formações puramente fictícias que não comportam em si nenhum indício do aspecto de realidade então a obra permanece para nós algo de irrelevante, morto, dispensável, a sua polifonia valiosamente qualitativa não tem possibilidade de se desenvolver [...].
}

Como afirma uma das maiores escritoras e estudiosas de ficção científica, Ursula Le Guin (1992: 36), a imaginação é «o jogo livre da mente, tanto intelectual quanto sensorial», e 
o resultado desse jogo livre no caso de uma mente adulta tanto pode ser Guerra e paz como a teoria da relatividade. Outra famosa escritora deste género, Margaret Atwood (e é curioso notar o elevado número de mulheres presentes no território da ficção científica, o que, segundo Le Guin, tem que ver com um particular uso muito livre da imaginação, capacidade tendencialmente feminina), faz a seguinte distinção: a ficção científica literária é a literatura que «descende da Guerra dos Mundos, de H.G. Wells», ou seja, «coisas que não poderiam acontecer», enquanto «plots that descend from Jules Verne's books about submarines and balloon travel and such is "speculative fiction": things that really could happen but just hadn't completed when the authors wrote the books» (Atwood, 2012: 6). Curiosamente, Atwood observa que, numa discussão pública com Ursula Le Guin, ela verificou que «what Le Guin means by "science fiction" is speculative fiction about things that really could happen, whereas things that really could not happen she classifies under fantasy».

Mas Ursula Le Guin, embora faça a distinção entre estes dois subgéneros, não pretende subavaliar a importância da fantasia, a qual, nas suas palavras «like any other art responsably created, can present both truth and the joy of the imagination» (Le Guin, 1992: 18). E num dos seus importantes ensaios sobre fantasia e ficção científica, intitulado «Why are Americans afraid of dragons?», incluído na obra The Language of the Night (Le Guin, 1992: 40), ela explica:

\begin{abstract}
Fantasy is true, of course. It isn't factual, but it is true. Children know that. Adults know it too, and that is precisely why many of them are afraid of fantasy. They know that its truth challenges, even threatens, all that is false, all that is phony, unnecessary, and trivial in the life they have let themselves be forced into living. They are afraid of dragons, because they are afraid of freedom.
\end{abstract}

Para esta autora, só uma mentalidade excessivamente tecnológica, comercial e funcional, de raízes puritanas - ou seja, que condena o prazer que não dá lucro -, é que explica que ficção científica possa servista com maus olhos. Ao explicar como descobriu a sua vocação de escritora deste género, através da leitura extasiada do livro A dreamer's tales, de Dunsany, reflete sobre a relação que existe entre o espírito científico e o gosto pela fantasia; noutro âmbito afirma não gostar de planear, por não ser engenheira, mas sim de descobrir, por ser exploradora, fazendo, assim, uma aproximação ao universo da ciência e afastando-se dos territórios mais tecnológicos. 0 mesmo paralelo acontece na seguinte passagem:

The book belonged to my father, a scientist, and was a favorite of his; in fact he had a large appetite for fantasy. I have wondered if there isn't some real connection between a certain kind of scientific-mindedness (the explorative, synthetizing kind) and fantasy-mindedness. 
Perhaps «science-fiction» really isn't such a bad name for our genre after all. Those who dislike fantasy are very often equally bored or repelled by science. They don't like either hobbits or quasars. (Le Guin, 1992: 21)

E conclui este ensaio com a seguinte ideia, muito inteligente e provocadora:

It is by such statements as «Once upon a time there was a dragon» or «In a hole in the ground there lived a hobbit» - it is by such beautiful non-facts that we fantastic human beings may arrive, in our peculiar fashion, at the truth. (Le Guin, 1992: 40)

Ou seja, a capacidade de imaginar é essencial para a descoberta do real (tanto pela via dos factos reais quanto pela via dos factos imaginados).

Vários filmes de ficção científica têm arriscado tratar precisamente as complexas questões do tempo, da memória e dos sonhos. Um dos mais famosos é Solaris, de Andrei Tarkovsky (1972), que teve uma versão 30 anos depois, em 2002, realizada por James Cameron. 0 cineasta russo fez uma complexa alegoria acerca do desejo de conhecimento e da dificuldade de relação do ser humano com o cosmos. Durante a estadia numa nave espacial, com a finalidade de estudar um planeta desconhecido chamado Solaris, que se assemelha a um gigantesco oceano cheio de uma espécie de energia «viva», um conjunto de cientistas começa a experimentar acontecimentos muito misteriosos e perturbadores. Na verdade, a bordo da nave começam a aparecer pessoas - ou imagens de pessoas - relacionadas com a vida de cada um deles, tal como se ali estivessem em carne e osso, vindo cada um a aperceber-se de que elas consistem na materialização das suas memórias pessoais. Como é dito por uma das personagens num dos diálogos, «Tudo indica que o oceano sondou os nossos cérebros, tirando deles alguma coisa semelhante a pequenas ilhas de memória». A noção agostiniana de «vestígio» ${ }^{16}$ é, neste caso, potenciada ao máximo, já que esses vestígios adquirem materialidade, fisicidade, obrigando cada um a lidar com eles. Como afirma um dos cientistas no momento da chegada de um novo colega de trabalho à nave, «isto não é demência, acho que é um problema de consciência». O dilema com que os cientistas terão de lidar é, sobretudo, pessoal: é a luta de cada um deles com o seu próprio mundo interior, bem como o drama da relação que estabelecem com os outros e com o universo a partir da sua consciência pessoal.

\footnotetext{
${ }^{16}$ Santo Agostinho, nas suas Confissões (1990: 308), dizia que «ainda que se narrem os acontecimentos verídicos já passados, a memória relata, não os próprios acontecimentos que já decorreram, mas sim as palavras concebidas pelas imagens daqueles factos, os quais, ao passarem pelos sentidos, gravaram no espírito uma espécie de vestígios». Ao discorrer sobre esta definição, Paul Ricoeur (1983:44) sintetiza: recordar é «ter uma imagem do passado».
} 
Quase sempre alegoria da vida, como sublinhava Ursula le Guin, a ficção científica ensaia caminhos de reflexão sobre o ser humano, os seus desejos e receios, as fronteiras de conhecimento que o atraem e provocam a explorar outros mundos. Nesta sua busca muito mais séria do que a etiqueta de «entretenimento» pode levar a crer, este género da literatura e do cinema torna-se também lugar de reflexão ética, neste caso sobre a necessidade radical de manter a absoluta inviolabilidade da mente humana, território sagrado da consciência individual e da identidade pessoal, bem como manifestação da dimensão mais profunda do humano. Como dizia Tarkovsky, «todos os mistérios do cosmos não têm comparação com a profundidade da alma humana», pelo que poderíamos acrescentar que são também infinitas as possibilidades de um género ficcional que assenta na construção de imagens sem correspondência direta com o real, embora decorrentes deste, e cuja meta é sempre, de algum modo, a tentativa de desvendar enigmas para alcançar a «verdade». Como afirmava também Doris Lessing, as histórias de ficção científica são frequentemente "profecias verdadeiras» - o que não admira, porque, como lembrava mesma autora, «a ficção científica - literária ou fílmica - é uma forma de oferecer novos horizontes à mente humana em expansão».

Num tempo dominado pelas imagens e pela sua força persuasiva - potenciada pela proliferação de usos facilitados pelos meios técnicos e comunicacionais que a Internet e a web ampliam de forma exponencial, enveredando por territórios nunca antes explorados -, não pode deixar-se de lembrar a questão que é colocada no filme de Christopher Nolan Inception (2010): será que viremos a necessitar de usar um pião cuja rotação não infinita nos assegure que estamos no terreno da realidade e não no da mera imagem ou da pura imaginação? Será que a relação entre a imagem «virtual» e a realidade é, de algum modo, substancialmente diferente? Que implicações podem resultar, em termos gnoseológicos, dessa eventual diferença - e como manter a nossa liberdade crítica num mundo onde esta «nova» imagem parece tornar-se omnipresente e omnipotente? O presente ensaio pretendeu oferecer algumas pistas de reflexão que possam ser subsidiárias para levar por diante uma análise que se pretende esclarecedora e pertinente no âmbito em que aqui nos movemos.

\section{Bibliografia}

Atwood, M. (2012). In Other Worlds. SF and the Human Imagination. (2. ${ }^{a}$ ed.). Virago Press. London;

Barthes, R. (1989). A câmara clara. Edições 70. Lisboa;

Bazin, A. (1992). O que é o cinema? Livros Horizonte. Lisboa;

Deleuze, G. (1985). L'image - Temps. Paris. Les Éditions de Minuit;

Guardini, R. (1954). L'opera d'arte. Milano. Edizioni Corsia dei Servi;

Ingarden, R. (1979). A obra de arte literária. Fundação Calouste Gulbenkian. Lisboa; 
Le Guin, U.K. (1989). The Language of the Night. Essays on Fantasy and Science Fiction. Women's Press. London;

McFarlane, B. (1996). Novel to Film. An Introduction to the Theory of Adaptation. Clarendon Press. Oxford;

Mitchell, W.J.T. (1987). Image, Text, Ideology. The University of Chicago Press. Chicago/London;

Mondzain, M.-J. (2013). Homo Spectator. Bayard. Montrouge;

Monteiro, P.F. (1995). Autos da alma: Os guiões de ficção do cinema português entre 1961 e 1990. Tese de Doutoramento em Ciências da Comunicação. Universidade Nova de Lisboa,
Faculdade de Ciências Sociais e Humanas. Lisboa. 1122 pp.;

Naremore, J. (ed.) (2000). Film Adaptation. The Athlone Press. London;

O'Connor, F. (1997). Mystery and Manners. Occasional Prose. (Sel. e ed. de Sally e Robert Fitzgerald). The Noonday Press. New York;

Ricoeur, P. (1987). Teoria da interpretação. O discurso e o excesso de significação. Edições 70. Lisboa;

Santo Agostinho (1990). Confissões. (12. ${ }^{a}$ ed.). (Trad. de J. Oliveira Santos e A. Ambrósio de Pina). Livraria Apostolado da Imprensa. Braga. 